\title{
Analisis Penerapan Produksi Bersih Pengelolaan Sampah di Tempat Pembuangan Akhir (TPA) Bakunci Kabupaten Tanah Laut
}

\author{
The Implementation Of Cleaner Production Waste Management In Landfill Bakunci \\ Kabupaten Tanah Laut
}

\author{
Meldayanoor $^{1^{*}}$, Mariatul Kiptiah $^{1}$, Dian Permata Sari ${ }^{1}$ \\ ${ }^{1}$ Jurusan Teknologi Industri Pertanian, Politeknik Negeri Tanah Laut, Jl. A. Yani, Km.6, \\ Desa Panggung, Kec. Pelaihari, Kab. Tanah Laut, Kalimantan Selatan 70815, Indonesia \\ Email: meldayanoor@politala.ac.id
}

Naskah diterima: 19 Agustus 2019; Naskah disetujui : 12 September 2019

\begin{abstract}
The current problem of waste has become a matter that requires attention, because garbage that is not managed properly will have a negative impact on the environment. The study was conducted at the Bakunci Landfill District of Tanah Laut. The purpose of this research is to analyze waste management in Bakunci Landfill and analyze the application of clean production in terms of technical feasibility, environmental feasibility and economic viability. The methods used in this study are interviews, questionnaires, direct observations and literature studies related to research. Waste management in the Bakunci Landfill is processing organic waste processed into compost, organic waste is processed into biogas and inorganic waste is managed in a garbage bank. In terms of the technical feasibility of compost management and the waste bank it is feasible to proceed, whereas in terms of environmental feasibility, every waste management undertaken has no effect on the environment. In terms of economic feasibility in compost management, the estimated profit is $\mathrm{Rp}$. 23,856,000/ month and waste bank management that is $28,818,900 /$ month for 33 garbage bank customers.
\end{abstract}

Keywords: Cleaner production, Waste and Final Disposal (TPA)

\begin{abstract}
ABSTRAK
Permasalahan sampah saat ini menjadi suatu hal yang memerlukan perhatian, karena sampah-sampah yang dibiarkan saja akan menimbulkan dampak negatif bagi lingkungan. Penelitian ini dilakukan di Tempat Pembuangan Akhir (TPA) Bakunci Kabupaten Tanah Laut. Tujuan dari penelitian ini yaitu untuk menganalisis pengolahan sampah di TPA Bakunci serta menganalisis penerapan produksi bersih dari segi kelayakan teknis, kelayakan lingkungan dan kelayakan ekonomi. Metode yang digunakan dalam penelitian ini yaitu wawancara, kuisioner, pengamatan langsung dan studi pustaka yang berkaitan dengan penelitian. Pengelolaan sampah di TPA Bakunci yaitu mengolah sampah organik diolah menjadi kompos, sampah organik diolah menjadi biogas dan sampah anorganik dikelola dibank sampah. Dilihat dari segi kelayakan teknis pengelolaan kompos dan bank sampah layak untuk dilanjutkan, sedangkan dari segi kelayakan lingkungan setiap pengelolaan sampah yang dilakukan tidak ada pengaruhnya terhadap lingkungan. Dilihat dari segi kelayakan ekonomi dalam pengelolaan kompos perkiraan keuntungan yang
\end{abstract}


diperoleh yaitu Rp. 23.856.000/bulan dan pengelolaan bank sampah yaitu 28.818.900/bulan untuk 33 nasabah bank sampah.

Kata kunci: Produksi bersih, Sampah dan Tempat Pembuangan Akhir (TPA)

\section{PENDAHULUAN}

Permasalahan sampah saat ini menjadi suatu hal yang memerlukan perhatian khusus karena sampah-sampah yang dibiarkan saja akan menimbulkan dampak negatif bagi lingkungan. Sampah menjadi salah satu permasalahan nasional bahkan dunia karena masih belum bisa diatasi sampai saat ini. Menurut Jambeck et al (2015), Indonesia berada pada peringkat tertinggi kedua di dunia setelah Cina sebagai penghasil sampah. Sistem pengelolaan sampah yang dilakukan di Indonesia sampai saat ini masih secara konvensional, yakni sistem kumpul-angkut-buang yang mengakibatkan dampak buruk bagi lingkungan. Tempat Pembuangan Akhir (TPA) sudah tidak dapat dikelola dengan baik karena semakin meningkatnya volume timbunan sampah.

Peningkatan volume sampah setiap tahunnya dipengaruhi oleh pertumbuhan penduduk. Peningkatan jumlah penduduk dan volume sampah tersebut hampir terjadi merata di seluruh wilayah Indonesia. Menurut Mutiarasyani (2018), Fakta bahwa pemanfaatan sampah dapat diolah untuk menghasilkan material-material yang dapat dipasarkan dan dikelola, sehingga kegiatan penanganan sampah secara eksklusif yang ditangani oleh pemerintah kota dapat diatasi.

Produksi bersih adalah strategi pengelolaan lingkungan yang sifatnya mengarah pada pencegahan dan terpadu untuk diterapkan pada seluruh siklus produksi. TPA Bakunci Kabupaten Tanah Laut sudah menerapkan salah satu prinsip produksi bersih yaitu pengurangan sampah dengan mengolah sampah menjadi kompos, biogas dan bank sampah. Hal tersebut yang melatarbelakangi penelitian ini agar dapat mengetahui pengolahan sampah di TPA Bakunci serta penerapan produksi bersih yang diterapkan di TPA Bakunci dan menganalisis kelayakan ekonomi, lingkungan dan juga kelayakan teknis.

\section{METODE PENELITIAN}

Penelitian ini dilakukan di Tempat Pembuangan Akhir (TPA) Bakunci Desa Karang Taruna Kecamatan Pelaihari Kabupaten Tanah Laut. 


\section{Tahap Pengumpulan Data}

Melakukan observasi ke lokasi penelitian yaitu di Tempat Pembuangan Akhir (TPA) Bakunci Desa Karang Taruna Kecamatan Pelaihari Kabupaten Tanah Laut. Dilanjutkan tahap wawancara kepada 8 orang responden yaitu penanggung Jawab TPA, Koordinator Bank sampah, nasabah bank sampah, koordinator kompos dan karyawan kompos.

\section{Prosedur Analisis Produksi Bersih}

Analisis Kelayakan Teknis dengan penilaian skala $1=$ kurang layak (untuk dilajutkan), 3 = layak (untuk dilanjutkan) dan $5=$ sangat layak (untuk dilanjutkan). Skor ini yang akan menentukan apakah pengelolaan sampah di TPA Bakunci layak untuk dilanjutkan.

Analisis Kelayakan Lingkungan dengan penilaian skala 1 = ada pengaruhnya (negatif terhadap lingkungan), 3 = tidak ada pengaruhnya (negatif terhadap lingkungan) dan $5=$ sangat tidak ada pengaruhnya (negatif terhadap lingkungan).

Analisis kelayakan ekonomi dihitung Dengan rumus :

Keuntungan $=$ pendapatan yang diperoleh - biaya yang dikeluarkan .

\section{HASIL DAN PEMBAHASAN}

\section{Pengelolaan Sampah di TPA Bakunci}

Jumlah sampah yang dikelola di TPA Bakunci disajikan pada Tabel 1 berikut.

Tabel 1. Data jumlah sampah yang dikelola di TPA Bakunci selama satu tahun

\begin{tabular}{cccccc}
\hline Bulan/tahun & $\begin{array}{c}\text { jumlah Sampah } \\
\text { TPA (Kg) }\end{array}$ & $\begin{array}{c}\text { Kompos } \\
(\mathbf{K g})\end{array}$ & $\begin{array}{c}\text { Bank } \\
\text { Sampah }(\mathbf{K g})\end{array}$ & $\begin{array}{c}\text { Biogas } \\
(\mathbf{K g})\end{array}$ & $\begin{array}{c}\text { sampah tak } \\
\text { diolah (Kg) }\end{array}$ \\
\hline Mar-18 & 1.027 .970 & 102.797 & 17.546 & 462.508 & 445.119 \\
Apr-18 & 1.003 .440 & 100.344 & 14.550 & 451.548 & 436.998 \\
Mei-18 & 989.430 & 98.943 & 17.907 & 445.243 & 427.337 \\
Jun-18 & 940.750 & 94.075 & 17.244 & 423.337 & 406.094 \\
Jul-18 & 1.050 .110 & 105.011 & 17.027 & 472.549 & 455.523 \\
Agu-18 & 1.023 .330 & 102.333 & 16.589 & 460.498 & 443.910 \\
Sep-18 & 1.069 .790 & 106.979 & 19.874 & 481.405 & 461.532 \\
Oktober & 919.790 & 91.979 & 21.288 & 413.905 & 392.618 \\
Nov-18 & 1.142 .340 & 114.234 & 22.201 & 514.053 & 491.852 \\
Desember & 1.226 .200 & 122.620 & 27.005 & 551.790 & 524.785 \\
Jan-19 & 1.041 .310 & 104.131 & 23.223 & 468.589 & 445.368 \\
Feb-19 & 1.151 .110 & 115.111 & 20.151 & 517.999 & 497.889 \\
Jumlah & $\mathbf{1 2 . 5 8 5 . 5 7 0}$ & $\mathbf{1 . 2 5 8 . 5 5 7}$ & $\mathbf{2 3 4 . 6 0 5}$ & $\mathbf{5 . 6 6 3 . 4 2 4}$ & $\mathbf{5 . 4 2 9 . 0 2 5}$ \\
\hline
\end{tabular}


Data jumlah sampah yang diperoleh dengan observasi langsung ke lapangan menunjukkan jumlah sampah yang diterima dan diolah selama satu tahun menunjukkan sebanyak 12.585.570 Kg. Banyaknya sampah yang sudah diolah menjadi kompos sebanyak $1.258 .557 \mathrm{Kg}$ dan sampah anorganik yang telah dikelola di bank sampah selama satu tahun yaitu sebanyak $234.564 \mathrm{Kg}$, sedangkan untuk sampah yang diolah menjadi biogas sekitar 5.663.424 Kg. Sampah yang diolah menjadi biogas dan kompos merupakan sampah yang tidak dikelola di bank sampah. Selama satu tahun lamanya sampah yang paling banyak diterima yaitu pada bulan Desemeber 2018. Menurut BLH Kabupaten Sleman (2014) peningkatan jumlah penduduk mengakibatkan peningkatan jumlah sampah yang dihasilkan, karena setiap aktifitas baik itu pribadi, kelompok, di rumah, kantor, pasar, sekolah maupun dimana saja akan akan menghasilkan sampah baik itu sampah organik maupun sampah anorganik.

\section{Analisis Produksi Bersih}

A. Analisis Kelayakan Teknis

Analisis kelayakan teknis produksi bersih sampah di TPA Bakunci disajikan pada Tabel 2.

Pengolahan sampah menjadi kompos jika dilihat dari segi kelayakan teknis skor rata-rata yang diberikan yaitu 3 yang artinya layak untuk dilanjutkan alasannya karena dari pemilihan mesin yang digunakan sudah efisien. Tahapan proses pengolahan kompos yang dilakukan sudah sesuai dengan hasil produksi yang dihasilkan. Sedangkan mengenai tata letak produksi pengolahan kompos mampu mempercepat produksi kompos sehingga tidak akan ada waktu yang terbuang setiap proses pengolahan kompos dilakukan. Pemilihan lokasi pengolahan kompos sudah baik karena berada tidak jauh dari bahan baku pengolahan.

Pengolahan biogas di TPA Bakunci memiliki skor nilai rata-rata yaitu 2 yang artinya hampir mendekati layak untuk dilanjutkan. Hal ini dikarenakan masih ada mesin yang belum dimiliki sehingga pemanfaatan biogas belum termanfaatkan keseluruhnya sehingga dari segi hasil produksi biogas yang dihasilkan maupun tahapan proses pengolahan harus diperbaiki agar pengolahan biogas di TPA Bakunci layak untuk dilanjutkan dan mampu memberikan manfaat bagi masyarakat maupun keuntungan bagi pihak pengelola biogas. 
Tabel 2. Ceklis Analisis Kelayakan Teknis

\begin{tabular}{|c|c|c|c|c|c|c|c|c|c|c|}
\hline \multirow{2}{*}{ No } & Analisis kelayakan & \multicolumn{8}{|c|}{ Responden } & \multirow{2}{*}{ Rata-rat: } \\
\hline & teknis & 1 & 2 & 3 & 4 & 5 & 6 & 7 & 8 & \\
\hline \multirow[t]{7}{*}{1.} & \multicolumn{9}{|c|}{ kelayakan teknis pengolahan Kompos } & \\
\hline & $\begin{array}{l}\text { Pemilihan mesin } \\
\text { pengolahan kompos }\end{array}$ & 3 & & & & & 3 & 1 & 1 & 2 \\
\hline & $\begin{array}{l}\text { Tahapan proses } \\
\text { pengolahan kompos }\end{array}$ & 3 & & & & & 3 & 3 & 3 & 3 \\
\hline & Produksi kompos & 3 & & & & & 3 & 3 & 3 & 3 \\
\hline & $\begin{array}{l}\text { Letak lokasi dan layout } \\
\text { pengolahan kompos }\end{array}$ & 3 & & & & & 3 & 3 & 3 & 3 \\
\hline & Pemilihan lokasi TPA & 5 & & & & & 3 & 5 & 3 & 4 \\
\hline & & & & & & & & & & 3 \\
\hline 2. & \multicolumn{9}{|c|}{ Kelayakan teknis pengolahan biogas } & \\
\hline & $\begin{array}{l}\text { Pemilihan mesin } \\
\text { pengolahan biogas }\end{array}$ & 3 & & & & & & & & 3 \\
\hline & $\begin{array}{l}\text { Tahapan proses } \\
\text { pengolahan biogas }\end{array}$ & 1 & & & & & & & & 1 \\
\hline & Produksi biogas & 1 & & & & & & & & 1 \\
\hline & Pemilihan lokasi TPA & 3 & & & & & & & & 3 \\
\hline & & & & & & & & & & 2 \\
\hline \multirow[t]{7}{*}{3.} & \multicolumn{9}{|c|}{ Kelayakan teknis bank sampah } & \\
\hline & $\begin{array}{l}\text { Pemilihan mesin dibank } \\
\text { sampah }\end{array}$ & 3 & 3 & 3 & 3 & 3 & & & & 3 \\
\hline & $\begin{array}{l}\text { Tahapan proses dibank } \\
\text { sampah }\end{array}$ & 3 & 3 & 3 & 3 & 3 & & & & 3 \\
\hline & $\begin{array}{l}\text { Produksi sampah } \\
\text { anorganik yang dihasilkan } \\
\text { dibank sampah }\end{array}$ & 3 & 3 & 3 & 3 & 3 & & & & 3 \\
\hline & $\begin{array}{l}\text { Letak lokasi dan layout } \\
\text { dibank sampah }\end{array}$ & 3 & 3 & 3 & 3 & 3 & & & & 3 \\
\hline & $\begin{array}{l}\text { Kedekatan bahan baku } \\
\text { dengan tenaga kerja }\end{array}$ & 3 & 3 & 3 & 3 & 3 & & & & 3 \\
\hline & Pemilihan lokasi TPA & 3 & 3 & 3 & 3 & 3 & & & & $\begin{array}{l}3 \\
3\end{array}$ \\
\hline
\end{tabular}

Pengolahan sampah anorganik di bank sampah skor rata-rata yang diberikan yaitu 3 yang artinya layak untuk dilanjutkan. Pemilihan peralatan seperti timbangan dan satu set komputer yang digunakan petugas mampu mempercepat proses penimbangan sampah sehingga mempersingkat waktu kerja. pemilihan lokasi bank sampah yang dekat dengan proses pemilahan mempermudah para nasabah membawa hasil pemilahan kepada petugas bank sampah.

B. Analisis Kelayakan Lingkungan

Analisis kelayakan lingkungan produksi bersih sampah di TPA Bakunci disajikan pada Tabel 3 berikut.

Tabel 3. Ceklis Analisis Kelayakan Lingkungan 


\begin{tabular}{|c|c|c|c|c|c|c|c|c|c|c|c|}
\hline \multirow[b]{2}{*}{ No } & \multirow[b]{2}{*}{ Pertanyaan } & \multicolumn{8}{|c|}{ Responden } & \multirow{2}{*}{$\begin{array}{c}\text { Jumlah } \\
\text { skor }\end{array}$} & \multirow{2}{*}{$\begin{array}{l}\text { Rata } \\
\text {-rata }\end{array}$} \\
\hline & & 1 & 2 & 3 & 4 & 5 & 6 & 7 & 8 & & \\
\hline 1. & kualitas air di sekitar TPA & 5 & 5 & 5 & 5 & 5 & 5 & 5 & 5 & 40 & 5 \\
\hline 2. & $\begin{array}{l}\text { Kontaminasi air oleh polutan } \\
\text { didalam tanah }\end{array}$ & 5 & 5 & 5 & 5 & 5 & 5 & 5 & 5 & 40 & 5 \\
\hline 3. & $\begin{array}{l}\text { Pembusukan sampah } \\
\text { menyebabkan bau udara sekitar }\end{array}$ & 1 & 3 & 3 & 1 & 1 & 1 & 3 & 3 & 16 & 2 \\
\hline 4. & Asap dan debu disekitar TPA & 3 & 3 & 3 & 1 & 1 & 3 & 1 & 1 & 16 & 2 \\
\hline 5. & $\begin{array}{l}\text { Perubahan karakteristik } \\
\text { permukaan lahan seperti tidak } \\
\text { rata dan rusak }\end{array}$ & 5 & 5 & 5 & 5 & 5 & 5 & 5 & 5 & 40 & 5 \\
\hline
\end{tabular}

Berdasarkan kuisoner yang diajukan kepada setiap responden yaitu mengenai kualitas air disekitar TPA Bakunci kurang bagus, setiap responden memberikan nilai skor rata-rata $5 \mathrm{Hal}$ ini karena keberadaan TPA yang jauh dari sumber air sehingga tidak mempengaruhi kualitas air yang dikonsumsi oleh masyarakat sekitar. Sedangkan mengenai kontaminasi air akibat polutan di dalam tanah responden memberikan skor ratarata yaitu 5 yang artinya tidak berpengaruh terhadap lingkungan. Hal ini karena jarak TPA yang jauh dari pemukiman warga yang memiliki jarak kurang lebih $6 \mathrm{~km}$ dari perumahan warga. Pembusukan sampah yang mencemari udara skor rata-rata nilai yang diberikan oleh responden yaitu 2 yang artinya mendekati berpengaruh. Hal ini dikarenakan truk-truk sampah yang mengankut sampah dari TPS ke TPA melalui perkampungan sehingga ketika truk sampah melewati akan tercium aroma tidak sedap yang memungkinkan akan menganggu warga sekitar. Asap dan debu atau keadaan tanah di lingkungan sekitar TPA skor yang diberikan responden yaitu 5 yang artinya tidak berpengaruh terhadap lingkungan karena keadaan tanah sekitar TPA tidak mengalami masalah.

\section{Analisis Kelayakan Ekonomi}

Analisis kelayakan ekonomi pengelolaan kompos disajikan pada Tabel 4 berikut.

Tabel 4. Analisis ekonomi pengolahan kompos

\begin{tabular}{ll}
\hline Biaya pengeluaran & \\
\hline Kemasan & Rp. $6.200 .000 /$ bulan \\
EM4 & Rp. $7.75000 /$ bulan \\
Total & Rp. $6.975 .000 /$ bulan \\
Perkiraan Pendapatan & \\
Kompos yang dihasilkan & $31.464 \mathrm{Kg} / \mathrm{bulan}$ \\
Harga kompos & Rp. $1000 / \mathrm{Kg}$ \\
Total & Rp. $31.464 .000 / \mathrm{bulan}$ \\
\hline
\end{tabular}


Analisis kelayakan ekonomi pengolahan kompos yaitu dari setiap jumlah sampah yang diolah menjadi kompos hanya 30\% siap pakai dari rata-rata sampah yang diolah menjadi kompos (data jumlah sampah pada tabel 1), hal tersebut dikarenakan ada penyusutan dan perombakan sampah-sampah yang telah melalui berbagai tahapan proses. Biaya yang dikeluarkan diperkirakan mencapai Rp. 6.975 .000 setiap bulannya. Biaya ini meliputi biaya kemasan karung berukuran 5 kg dengan harga satuan karung yaitu Rp. 1000,00 maka agar mampu mengemas semua kompos yang telah jadi maka biaya yang dikeluarkan untuk kemasan berkisar Rp. 6.200.000/bulan. Sedangkan untuk biaya tambahan dalam pengelolaan kompos seperti penggunaan EM4 sebanyak 31 botol ukuran 1 liter dengan harga berkisar Rp. 7.75000/bulan. Jumlah kompos yang mampu dihasilkan dalam setiap bulannya yaitu 30\% dari sampah yang diolah maka kompos yang dihasilkan sebanyak $31.464 \mathrm{Kg}$. Harga jual kompos yaitu Rp. 1000,00/ Kg. Maka perkiraan pendapatan yang akan diperoleh setiap satu bulan dalam penjualan kompos yaitu $\mathrm{Rp}$. 31.464.000. dilihat dari total perkiraan pendapatan yang diperoleh jika nilai pendapatan dikurang dengan biaya yang dikeluarkan maka taksiran keuntungan yang dihasilkan dalam pengelolaan sampah menjadi kompos selama satu bulan yaitu sebesar Rp. 24.489.000.

Analisis kelayakan ekonomi pengelolaan dibank sampah disajikan pada tabel 5 berikut.

Tabel 5. Data pendapatan salah satu nasabah bank sampah

\begin{tabular}{cccccc}
\hline Bulan & Sandi & Jumlah $(\mathbf{K g})$ & Harga $(\mathbf{K g})$ & Jumlah $\times$ harga & Total \\
\hline Desember & Pet & 140 & 1.100 & $182 \times 1.100$ & 154.000 \\
& GA & 150 & 2.700 & $241 \times 2.700$ & 283.500 \\
& Ember & 112 & 2.100 & $151 \times 2.100$ & 235.200 \\
& Kaleng & 52 & 400 & $52 \times 400$ & 20.800 \\
& Karung & 220 & 500 & $274 \times 500$ & 110.000 \\
& Sendal & 26 & 400 & $26 \times 400$ & 10.400 \\
& Besi & 18 & 2700 & $28 \times 2.700$ & 48.600 \\
& Sepatu & 6 & 1800 & $6 \times 1.800$ & 10.800 \\
& & & & & 873.300 \\
\hline
\end{tabular}

Pengolahan sampah anorganik di bank sampah yaitu setiap nasabah bank sampah hanya perlu memilah sampah sesuai kriteria yang dapat dijual kemudian menimbangnya kepada petugas bank sampah. Tidak ada biaya yang dikeluarkan oleh nasabah bank 
sampah. Sehingga sudah jelas bahwa keuntungan yang diperoleh oleh nasabah bank sampah cukup menguntungkan. Keuntungan yang diperoleh salah satu nasabah bank sampah selama satu bulan mencapai Rp. 873.300 jika jumlah keseluruhan nasabah bank sampah mencapai 33 nasabah maka dalam satu bulan keuntungan yang diperoleh nasabah bank sampah mencapai Rp. 28.818.900.

\section{KESIMPULAN}

1. Pengelolaan sampah yang dilakukan di TPA Bakunci meliputi pengelolaan sampah organik menjadi kompos dan menjadi biogas, sedangkan pengelolaan sampah anorganik dilakukan di bank sampah.

2. Analisis produksi bersih pengelolaan sampah di TPA Bakunci dari segi kelayakan teknis pengelolaan sampah dibank sampah yang memiliki skor 3 yang artinya layak untuk dilanjutkan, pengelolaan biogas dengan skor nilai 2 yang artinya mendekati layak untuk dilanjutkan sedangkan untuk pengelolaan kompos skor nilai 3 yang artinya layak untuk dilanjutkan. Dari segi kelayakan lingkungan dari seluruh pengelolaan sampah memiliki skor nilai 3 yang artinya sangat berpengaruh terhadap lingkungan. Dari segi kelayakan ekonomi dalam pengelolaan kompos mendapat keuntungan sebesar Rp. 23.856.000/bulan., sedangkan dalam pengelolaan biogas mampu mencukupi kebutuhan memasak di kantin TPA Bakunci dan dalam pengelolaan bank sampah keuntungan yang diperoleh nasabah bank sampah yaitu mencapai Rp. 28.818.900/bulan untuk 33 nasabah bank sampah.

\section{UCAPAN TERIMA KASIH}

Terima kasih kepada Program Studi Teknologi Industri Pertanian Politeknik Negeri Tanah Laut yang telah mendukung terlaksananya kegiatan penelitian.

\section{DAFTAR PUSTAKA}

Badan Lingkungan Hidup Kabupaten Sleman. 2014. Data Pengelolaan Sampah di Kabupaten Sleman.

Elpawati. 2015. Optimalisasi Penggunaan Pupuk Kompos Dengan Penambahan Effective Microorganism 10 (Em10) Pada Produktivitas Tanaman Jagung (Zea Mays L.). Jurnal Biologi. Vol. 8, No. 2, Hal 77-87. 
Hakimi, R., Budiman, D. 2006. Aplikasi Produksi Bersih (Cleaner Production) Pada Industri Nata De Coco, Jurnal Teknik Mesin, Vol. 3, No. 2, ISSN 1829-8958. Universitas Andalas. Padang.

Hasan A.R \& Putu W. 2014. Pembuatan Biogas Dari Sampah Pasar. Jurnal Ilmiah Teknik Lingkungan Vol. 6 No. 1. Hal 59-64. Jawa Timur.

Jambeck J.R, Geyer R. Wilcox C, Siegler T.R, Perryman M, Andrady A, Narayan R, Law K.L. 2015. Plastic Waste Inputs From Land Into the Ocean. Journal of Science. 347(6223): 768-770.

Kurniawan, Nalim. 2007. Analisis Kelayakan Usaha Pengolahan Sampah Kota Menjadi Produk Yang Berguna Di TPA Bantargebang. Universitas Gunadarma. Bekasi

Kusuma P.T. 2012. Analisis Kelayakan Finansial Pengembangan Usaha Kecil Menengah (Ukm) Nata De Coco. Vol. 01. No. 02. Hal 113-120. Jawa Barat.

Lumintang, M, Fatmawati. 2013. Analisis Pendapatan Petani Padi Di Desa Teep Kecamatan Langowan Timu. Fakultas Ekonomi dan Bisnis. Manado. Vol. 1. No. 3. 991-998.

Mutiarasyani. Y. 2018. Analisis Kelayakan Dan Skala Pengelolaan Bank Sampah Yang Berkelanjutan (Studi Kasus: Bank Sampah Srikandi Berdikari, Desa Pasarean, Kecamatan Pamijahan, Kabupaten Bogor). Departemen Ekonomi Sumber Daya Dan Lingkungan Fakultas Ekonomi Dan Manajemen Institut Pertanian Bogor.

Radityaningrum AD, Caroline J, Restianti DK. 2017. Potensi Reduce, Reuse, Recycle (3R) Sampah pada Bank Sampah 'Bank Junk for Surabaya Clean (BJSC)'. Jurnal Teknik Lingkungan. 03(01): 1-11.

Septiatri, Wulandari. 2014. Analisis Strategi Penerapan Produksi Bersih Pada Rantai Logistik Industri Hortikultura. Skripsi. Fakultas Teknologi Pertanian Institut Pertanian. Bogor.

Probowati, B. D., Burhan. 2011. Studi Penerapan Produksi Bersih Untuk Industri Kerupuk. Universitas Trunojoyo Madura. Madura. 